\title{
Global Justice and the Social Determinants of Health
}

\section{Sridhar Venkatapuram}

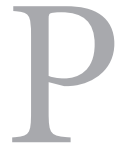

ublic scrutiny and deliberation are central to both the sciences and ethical reasoning. In the sciences, research findings and analyses are put forward in the public arena not simply to announce new evidence but also for public examination, to be either corroborated or disputed. In ethics there is a similar process, whereby reasoned arguments are put forward about what is the good or right thing to do. In either domain, knowledge is expanded through the coherence and acceptance of the analyses and arguments, which depends on their being able to withstand public scrutiny. Therefore, when scientific and ethical arguments are brought together, the task of public deliberation is twofold, as it must encompass the empirical and the normative; and when the arguments concern an issue of such enormous scope as global health inequalities, public deliberation has to include national and global domains.

It is precisely this kind of twofold public deliberation that the World Health Organization's (WHO) Commission on the Social Determinants of Health (CSDH) anticipated when it released its final report at the end of 2008. In that report, the commission combined epidemiological analysis of health inequalities within and across countries with an essentially cosmopolitan ethical argument for motivating global social action to mitigate ill health and health inequalities. By doing so the commission brought together the consideration of scientific evidence, the centrality of global public deliberation to global health, and a view on global social justice.

The two most notable aspects of the CSDH's report are that, first, it put forward a scientific analysis of the social causes of ill health and health inequalities within and across countries, and, second, it coupled the analysis with an ethical argument for acting to advance global health and health equity. ${ }^{1}$ The CSDH's report is the first to apply social epidemiological analysis to global health, which is distinct

Ethics \& International Affairs, 24, no. 2 (2010), pp. 119-130.

(C) 2010 Carnegie Council for Ethics in International Affairs 
from the prevailing analyses of the causes of ill health, which focus on such individual-level determinants as exposures to harmful agents, behaviors, and genetics, or those analyses that overlook social-group differences in health outcomes within countries. ${ }^{2}$ Moreover, the commission's justification for addressing ill health and health inequalities within and across countries is grounded in the ethics of justice, as opposed to such reasons as national security or interest, economic growth, charity, or a self-evident "contain and control" epidemiological imperative. The moral principle that informs the commission's work is that where one can do something to alleviate avoidable suffering through reasonable means, one should do so.

The CSDH's report appears to be a grand experiment to see whether science, linked with ethics, can motivate global action, and whether the public scrutiny and deliberation that are so central to scientific research and ethical reasoning can meaningfully be brought together in global health policy. Established in 2005 by the late J. W. Lee, then director-general of the WHO, the CSDH had three objectives: to collect and synthesize global evidence on the social determinants of health; assess their impact on health inequity; and make recommendations for action to address that inequity. The commission published its final report at the end of 2008, presenting that evidence as well as asserting that ill health and health inequalities that were preventable by reasonable means were manifest inequities that must be addressed as a matter of social justice. The work of the CSDH and the resultant final report are intended to instigate discussions - within national and international institutions and the global public sphere-as well as to help engender social action and policies to advance health and health equity within and across countries.

Since the final report was released, it has elicited reactions ranging from dismissive journalistic commentary (the Economist described its goals as "quixotic") to critically engaged scholarly reviews and various government-level conferences. ${ }^{3}$ Furthermore, a number of regional institutions and countries around the world, including Argentina, Brazil, Chile, Sri Lanka, and Thailand, are in the process of setting up their own commissions on the social determinants of health and health inequities. England set up a commission in late 2008, and already reported its findings in February 2009. ${ }^{4}$ The WHO Regional Office for Europe announced that it will also set up a commission, which will likely give special attention to the great health divide between western and eastern European countries. 
Yet the global reaction to the commission's findings, particularly by international institutions and development assistance agencies, seems to be noticeably muted in comparison to the reactions to the previous health-related commissions and reports produced by United Nations/Bretton Woods organizations. In terms of its intentions to shift paradigms, the commission's report stands among some other landmark global reports, such as the 1990 Human Development Report, which introduced the idea of human development and the Human Development Index (HDI); the 1993 World Development Report, which introduced the new health measurement of the Disability Adjusted Life Year (DALY); and the 2001 Report of the WHO Commission on Macroeconomics and Health (CMH), which advocated investing in health systems for the sake of economic growth. Even within a year, ideas such as the HDI, DALYs, and investing in health for growth found numerous advocates within global institutions. In comparison, the central ideas of the CSDH report - namely, the social determinants of health and the social gradient in health - appear to be getting a less enthusiastic reception. It is interesting to consider whether the comparatively different response from institutions that have major influence on national and global health has to do with problems of testimony; that is, whether the scientific status of the epidemiological analysis of social determinants of health is unconvincing - in contrast to the explanatory power of the economic analysis of previous landmark reports - and/or whether the combined scientific evidence and social justice argument does not have sufficient motivational power to move institutions and individuals from maintaining the status quo.

\section{Social Epidemiology and the Commission}

The commission put forward a new analytical framework for understanding and addressing population health issues within and across countries that directly competes with the prevailing approaches to global health policy, which focus on (a) containing specific diseases through "vertical" or stand-alone clinical and public health interventions, (b) improving health-systems performance, (c) pursuing cost-effective health interventions that will maximize DALYs, and/or (d) contributing to economic growth. Grounded in the discipline of social epidemiology and based on the collected research of global "knowledge networks," the commission's recommendations for social action span three overarching areas: (1) to improve the conditions of daily living - that is, the conditions in which people are born, grow, live, work, and age; (2) to tackle the "upstream drivers" of 
those conditions, specifically the inequitable distribution of power, income, and resources; and (3) to measure the problem, evaluate action, and carry out further research. Within these three areas the commission made further, more specific recommendations in twelve areas:

1. early child development and education

2. healthy places/the living environment

3. fair employment and decent work

4. social protection across the life course

5. universal health care

6. health equity in all policies

7. fair financing

8. market responsibility

9. gender equity

10. political empowerment

11. good global governance

12. knowledge, monitoring, and skills

Clearly, the commission's policy recommendations are quite general given the need to identify a framework and policy recommendations that are relevant and applicable to people throughout the world. As recognized by some governments taking up the commission's recommendations, such as in Latin America, Europe, and Asia, national or regional strategies to advance health and health equity require contextual analysis across the identified areas. Indeed, local commissions may find other areas for social action that are more immediately relevant determinants of health.

Underlying the commission's recommendations for policies to improve healthas opposed to health care policy that is confined to the health sector-is a scientific etiological framework that aims to explain the causation and distribution of ill health and mortality across individuals and social groups. The commission's social epidemiological framework contrasts with the "classic" model of epidemiology, in which the scope of research on the causes of disease is limited to individual-level factors that include individual biology, individual behaviors, and individual-level exposures to external harmful organisms and particles. These three categories of factors are often metaphorically described as making up a multifactorial "causal pie" or links in a "web of causation." 5 This individual-level "biomedical model" of disease has been increasingly challenged over the past two decades because 
of its persistent limitations in fully identifying the causes of many chronic and degenerative diseases, as well as its inability to explain the dynamics and distribution patterns of population-level health. ${ }^{6}$ Molecular epidemiology, which digs deeper in the individual, has been promoted as a panacea to the classic model's explanatory limitations. In contrast, social epidemiology, which focuses on supraindividual factors, and the basic tenets of its research have received considerably less public attention — despite their insights and productivity. ${ }^{7}$ This may or may not be surprising, depending on one's worldview, as social epidemiology brings together two very politically charged issues: that of the social causation of illness and mortality and the unequal social distribution of illness and mortality.

Moving away from the classic biomedical model that was dominant in the late twentieth century, social epidemiologists are expanding the causal chain outward from the proximate individual-level factors to include the causes of the proximate causes and their discrete and cumulative effects throughout the life cycle, starting from the womb. Social epidemiology also expands the causal chain upward to incorporate multiple levels of factors; that is, the political, economic, and social policies and processes that affect health are being quantified and integrated into an epidemiological model of causation and distribution of illness and mortality in individuals and groups. This bridging or integrating of the social and the biological has been characterized as a "Chinese boxes" paradigm. ${ }^{8}$ The metaphor aims to reflect the understanding that an individual's health is determined by multiple and increasingly distal factors, which at the same time profoundly shape the immediate context or the more proximate factors. Representing the first truly global application of social epidemiology, the commission articulated the causal nested framework in the following way:

1. The conditions of daily life in which individuals are born, grow, live, work, and age determine their experience of morbidity and length of life span.

2. These daily living conditions produce proximal determinants, such as exposures to harmful substances and biological risks; availability of material needs, such as food, potable water, shelter, and health care; as well as social environments that affect psychobiological pathways and health-related behaviors.

3. These daily conditions in turn have structural drivers or "causes of causes" - the economic, social, and political conditions that, together 
with background social and cultural norms, create and distribute the proximate causes across individuals and social groups.

The starting position of social epidemiology is that individual-level factors do not provide sufficient causal explanations for the significant health differences between groups of human beings defined by such social characteristics as nationality, education, income, occupation, gender, race/ethnicity, or geographical residence. The hypothesis is that factors created by the social environment have a significant influence in the causal pathways to illness in individuals and unequally distribute ill health across social groups. In a similar vein, the commission started from the premise that there is no biological causal explanation for the marked differences in life expectancies across countries; for example, the gross inequality in life expectancy between the Japanese (eighty-three years) and Malawians (forty-eight years) cannot be explained by differences in biological endowment. Rather, the commission argues that differences in life expectancies and health profiles are determined by social environments - by economic, political, and social policies and processes driven by social and cultural values that create and distribute the daily conditions of life.

Importantly, social epidemiological research not only explodes outward the classic model of epidemiology, but the research findings also militate against various social consequences of applying the biomedical model. Some of these social consequences include the narrow focus on providing health care and behavior change as the primary avenues to improve health; being inattentive to social group inequalities in health; exaggerating individual volition in health outcomes; and focusing on the material poverty of the most disadvantaged while ignoring psychosocial environments producing ill health in the entire population. Such drawbacks of an exclusively individual-level analysis are not a concern just for domestic health policies but also for global health policies, which can include, inter alia, development assistance for health programs, transnational health policies, or domestic health policies addressing extraterritorial health threats.

One of the seminal bodies of evidence that challenges the dominance of the classic model and its social consequences has come out of the Whitehall studies in England, led by Sir Michael Marmot, who also served as chair of the WHO commission. In the initial and follow-up Whitehall studies, conducted since the 1970s, researchers have observed a continuous and downward-sloping gradient in health achievements that parallel employment grades across British civil servants. 
Because all civil servants have access to health care, earn above living wage, and are not genetically selected to employment grades, the causes of ill health in individuals and social gradient health pointed to social conditions, particularly psychosocial pathways. ${ }^{9}$ The lack of autonomy/agency ("control") and social support has been shown to affect neuroendocrine pathways leading to disease. It has been further shown that these two psychosocial factors are distributed unequally across the employment grades. ${ }^{10}$

Following the Whitehall studies, the social gradient in health achievements has been corroborated as existing across the entire society in every industrialized country, and even in developing countries wherever research has been done. ${ }^{11}$ Such evidence of a continuous gradient in health across an entire society serves to undermine the notion that health is simply distributed along a threshold between the "haves" and "have-nots," and that the poor health of the richer group is due largely to lifestyle volitional behaviors or still unknown genetic risk factors. The conclusion, however, is not that the factors in classic epidemiology are not causally important, but that identifiable and measurable social factors influence psychobiological pathways to disease in individuals as well as determine the distribution or steepness of the social gradient of health achievements within societies and globally. The Whitehall studies are now part of a broader and growing body of research that examines the causal and distributional effects of social processes on individuals over the life course and on population health over time. $^{12}$

Reflecting the scope and insights of social epidemiology, the commission advocates a paradigm shift that would expand the current scope of analysis and action to include broader social factors: policies that are good for health, not just health care policies. The shift also entails the expansion of the focus on the health of the poor (or "ultra poor") to include the health gradient, or the health of the entire population. The expansion of scope, however, should not be understood as a diminution of either the importance of improving health care and health systems or of giving priority to the health of the materially worst off. Furthermore, at the global health policy level, the commission's social epidemiology framework provides a more refined account of the causes and distribution of ill health and health inequalities within and across countries than the blanket explanations of poverty, poor governance, or lack of education. Importantly, the CSDH asserts that the causes and distribution of health inequalities are linked to national as well as transnational social processes and policies. Thus, the commission has 
expanded the scope of epidemiology even further by including global processes and policies and their underlying global norms and values. For instance, the report presents an analysis of the health effects of global market integration, structural inequities in global trade relations, and transnational corporate influence. The commission makes many recommendations to counteract the negative health effects of such determinants - for example, recommending the inclusion of health impact assessments in any major transnational economic agreement. It also calls for more public sector leadership that aims to protect the public supply and regulate the private provision of health determinants, such as water and electricity, while controlling the market expansion of harmful goods, such as tobacco, alcohol, and cheap energy-dense and nutrient-poor foodstuffs.

The commission's report asserts that health issues in rich and poor countries alike can be examined using a single explanatory model, or "plane of observation." Using one causal model shows that preventable death and morbidity of the most disadvantaged as well as the entire social gradient in health achievements in both rich and poor countries are the result of the way we organize our societies (and the global society) through economic, social, and political policies and practices. This single causal model strongly contrasts with demographic/epidemiological transition models that are applied only at the national level and categorically divide the health issues of rich countries (chronic diseases) from those of poor countries (infectious diseases). A unified social epidemiology model also raises doubts about the robustness of economic models that assert that economic growth causally leads to reductions in health inequalities, and the related proposition that the most cost-effective "investments" are to be made in health systems to maximize DALYs or support economic growth. Simply put, the commission's message is that across all countries ill health and health inequalities are significantly determined by broad social factors outside the functioning of health systems, and those factors can be identified and acted upon.

While a thorough stakeholder analysis could be informative, there are several possible reasons why governments, international organizations, and health-related nongovernmental organizations have been muted in their response to the commission's report. First, the commission can be seen as disempowering health specialists by highlighting that the most significant determinants of health fall outside of health care. While the commission recommends universal access to health care, its broader analysis is partly motivated by the fact that in societies where every individual has access to health care, ill health and health inequalities will persist due 
to social factors. Health care is necessary but not sufficient to mitigate avoidable ill health and social inequalities in health. Second, the report emphasizes the entire social gradient in health in both rich and poor countries, which seems to take attention away from the worst off. Furthermore, by showing that the health of populations is determined largely by factors outside the influence of national health systems, it becomes difficult to identify which agent(s) is capable and, indeed, responsible for coordinating the appropriate response across numerous government departments and policy spheres. Health professionals in international organizations and research institutions will confront the same problem. Even though health professionals in international organizations, such as the World Bank, are increasingly recognizing the need to move away from vertical disease programs to programs that focus on strengthening health sectors or systems, these conversations about broadening the scope of policies are still only about health care, not health.

While the commission's recommendations raise such uncertainties about coordination and responsible agents, it does not ever suggest that it is misguided to continue to focus on improving health systems or alleviating material poverty; these determinants continue to be causal components within social determinants of health frameworks. As a result, the commission's analysis does not threaten the rationale of ongoing work of health organizations and individual health professionals or the continued focus on ameliorating poverty. In essence, health and poverty specialists are already in line with the social determinants of health framework. Rather, the commission seeks to expand the scope of analysis of health experts beyond health care and encourage non-health sector institutions and policymakers to understand the health effects of their spheres of influence and prioritize health in their own work. It is largely here at the point of motivating action beyond health care by health professionals, and establishing concern for health in nonhealth sectors, where the argument from social justice appears to be most relevant.

\section{The Ethics of Social Determinants of Health}

By locating significant causes of ill health and health inequalities in social phenomena, the commission recasts health inequalities as a central matter of social justice. If social factors are identified as determining such significant aspects of human well-being as mortality and morbidity, the moral responsibility for ill health and health inequalities expands beyond the individual to include social institutions 
and processes. This serves as a rejoinder to decades of concerted efforts in some developed countries to exclude "the social" from epidemiology and place the moral responsibility for health onto the individual. ${ }^{13}$ Nevertheless, for the commission, identifying the social origins of ill health and health inequalities is a necessary but insufficient step; the commission also asserts that there is a moral imperative to mitigate avoidable ill health and health inequalities if it is possible to do so through reasonable means. ${ }^{14}$

It is no coincidence that a similar principle is given an important place in Amartya Sen's arguments for realizing social justice in his The Idea of Justice. ${ }^{15}$ Aside from his direct role as a member of the commission, Sen's influence on the commission is enormous. Marmot and his colleagues saw an affinity between, on the one hand, the research on the role of autonomy/agency and social interactions on pathways to disease and, on the other hand, Sen's ideas about freedoms and capabilities. In essence, the commission tries to show that the social determinants of ill health and health inequalities are social constraints on human capabilities. Sen's argument that justice requires promoting capabilities and freedoms underlies the commission's message that ill health and health inequalities require social mitigation as a matter of social justice. Sen's long-standing arguments for reconceptualizing development as increasing freedoms and capabilities — in opposition to the predominant view of development as and for economic growth-also emboldened the commission's critique of the idea of addressing health for its instrumental value to economic growth, of the inattention to the social distribution patterns or inequalities in health, and of the role of economic inequalities in producing ill health and health inequalities.

The commission presents ethical justification for social action at the global level by arguing that where one has the power to prevent or mitigate injustice, one has sufficient reason to consider doing so. Sen terms this an "obligation from effective power." 16 The capacity to mitigate injustice is sufficient enough grounds to consider acting. The commission provides empirical evidence that a whole range of actors, including individuals within national governments and international organizations, have within their power the ability to prevent or mitigate ill health and gross health inequalities within and across countries through acting on the social determinants of health.

Given the expertise behind the commission, disparaging its analysis as unscientific or "quixotic" likely either demonstrates a lack of comprehension of epidemiology or is an attempt to belittle the identified ethical obligation for social 
action. Indeed, as with any epidemiological study, there should be meaningful scrutiny of the scientific methodology and analysis of the commission's report. However, the acceptance of the commission's framework and recommendations by individuals within national and international institutions is less likely to be a function of the trustworthiness of the science of social epidemiology and the commission's analysis and much more likely to reflect the current state of public reasoning about ethical obligations of effective power. As Sen writes, "Given what can be achieved through intelligent and human intervention, it is amazing how inactive and smug most societies are about the prevalence of the unshared burden of disability. In feeding this inaction, conceptual conservatism plays a significant role." 17 The commission breaks with the conceptual conservatism that pervades national and global health policy. However, it is an open question as to whether global public reasoning is sufficiently viable and robust to meaningfully engage and deliberate on the commission's report and then catalyze substantial action on the social determinants of health and health inequalities.

\section{NOTES}

1 The report and information about the commission are available at www.who.int/social_determinants/en/.

2 Paula Braveman et al., "World Health Report 2000: How It Removes Equity from the Agenda for Public Health Monitoring and Policy," British Medical Journal 323 (2001); and C. J. Murray, E. E. Gakidou, and J. Frenk, "Health Inequalities and Social Group Differences: What Should We Measure?" Bull World Health Organ 77, no. 7 (1999).

3 "The Price of Being Well," Economist, August 30, 2008; Tony Blakely, "Iconography and Commission on the Social Determinants of Health (and Health Inequity)," Journal of Epidemiology \& Community Health 62, no. 12 (2008); and M. Marmot and S. Friel, "Global Health Equity: Evidence for Action on the Social Determinants of Health,” Journal of Epidemiology \& Community Health 62, no. 12 (2008).

4 Information about the commission and report is available at the U.K. Department of Health website at www.dh.gov.uk/en/Publichealth/Healthinequalities/DH_09477o.

5 N. Krieger, "Epidemiology and Social Sciences: Towards a Critical Reengagement in the 21st Century," Epidemiologic Review 22, no. 1 (2000), pp. 155-63. Also see Kenneth J. Rothman, Sander Greenland, and Timothy L. Lash, Modern Epidemiology, 3rd ed. (Philadelphia: Wolters Kluwer Health/Lippincott Williams \& Wilkins, 2008).

${ }^{6}$ N. Krieger, "Epidemiology and the Web of Causation: Has Anyone Seen the Spider?" Social Science \& Medicine 39, no. 7 (1994); N. Krieger, "Theories for Social Epidemiology in the 21st Century: An Ecosocial Perspective," International Journal of Epidemiology 30, no. 4 (2001); M. Susser and E. Susser, "Choosing a Future for Epidemiology: I. Eras and Paradigms," American Journal of Public Health 86, no. 5 (1996); and M. Susser and E. Susser, "Choosing a Future for Epidemiology: II. From Black Box to Chinese Boxes and Eco-Epidemiology,” American Journal of Public Health 86, no. 5 (1996).

7 Social epidemiology as a distinct discipline is new, as evidenced by the publication of one of its first textbooks in 2000, Lisa F. Berkman and Ichiro Kawachi, Social Epidemiology (New York: Oxford University Press, 2000).

8 Susser and Susser, "Choosing a Future for Epidemiology: I. Eras and Paradigms"; and Susser and Susser, "Choosing a Future for Epidemiology: II."

9 Though a declining gradient in health achievements parallel to socioeconomic gradient across British society had long been observed, the identification of such a gradient within the subpopulation of British civil servants was very surprising and significant. Even after accounting for such behaviors as smoking, diet, and exercise, the gradient in health achievements is still clearly visible. The Whitehall study population, in effect, represented a microcosm of the broader society while allowing researchers to control for the various categories of individual-level factors, which include biology, behaviors, and material exposures and deprivations. See M. G. Marmot et al., "Health Inequalities among British Civil Servants: The Whitehall II Study," Lancet 337, no. 8754 (1991); and M. G. Marmot et al., "Employment 
Grade and Coronary Heart Disease in British Civil Servants," Journal of Epidemiology \& Community Health 32, no. 4 (1978).

10 E. Brunner, "Biology and Health Inequality," PLoS Biology 5, no. 11 (2007); J. Macleod and G. Davey Smith, "Psychosocial Factors and Public Health: A Suitable Case for Treatment?" Journal of Epidemiology \& Community Health 57, no. 8 (2003); and A. Singh-Manoux, "Psychosocial Factors and Public Health," Journal of Epidemiology \& Community Health 57, no. 8 (2003).

${ }^{11}$ P. Braveman and E. Tarimo, "Social Inequalities in Health within Countries: Not Only an Issue for Affluent Nations," Social Science \& Medicine 54, no. 11 (2002).

12 For a good overview of the field of social epidemiology, see Berkman and Kawachi, Social Epidemiology; and Richard Wilkinson and M. G. Marmot, Social Determinants of Health: The Solid Facts (Copenhagen: Centre for Urban Health, World Health Organization, Regional Office for Europe, 1998). Also see the journals Social Science \& Medicine and Journal of Epidemiology \& Community Health.

13 Krieger, "Epidemiology and the Web of Causation"; David Halpern et al., "Personal Responsibility and Changing Behaviour: The State of Knowledge and Its Implications for Public Policy," Cabinet Office, Prime Minister's Strategy Unit (2004); and D. I. Wikler, "Persuasion and Coercion for Health: Ethical Issues in Government Efforts to Change Life-Styles," Milbank Memorial Fund Quarterly 56, no. 3 (1978).

14 Peter Singer, "Outsiders: Our Obligations to Those Beyond Our Borders," in Deen K. Chatterjee, ed., The Ethics of Assistance: Morality and the Distant Needy, Cambridge Studies in Philosophy and Public Policy (Cambridge: Cambridge University Press, 2004).

15 Amartya Sen, The Idea of Justice (London: Allen Lane, 2009).

16 Ibid., pp. 205-07.

17 Ibid., p. 260. 